HYDRAULIC CONSIDERATIONS IN SAMPLING THE UNSATURATED ZONE WITH INCLINED GRAVITY LYS IMETERS

by Edward T. Oaksford

U.S. GEOLOGICAL SURVEY

Water-Resources Investigations Report 83-4005

Syosset, New York 


\section{UNITED STATES DEPARTMENT OF THE INTERIOR}

JAMES G. WATT, Secretary

GEOLOGICAL SURVEY

Dallas L. Peck, Di rector

For additional information write to:

U.S. Geological Survey

5 Aerial Way

Syosset, New York 11791
Copies of this report may be purchased from:

U.S. Geological Survey Open-File Services Section Western Distribution Branch Box 25425 Federal Center Denver, Colo. 80225 


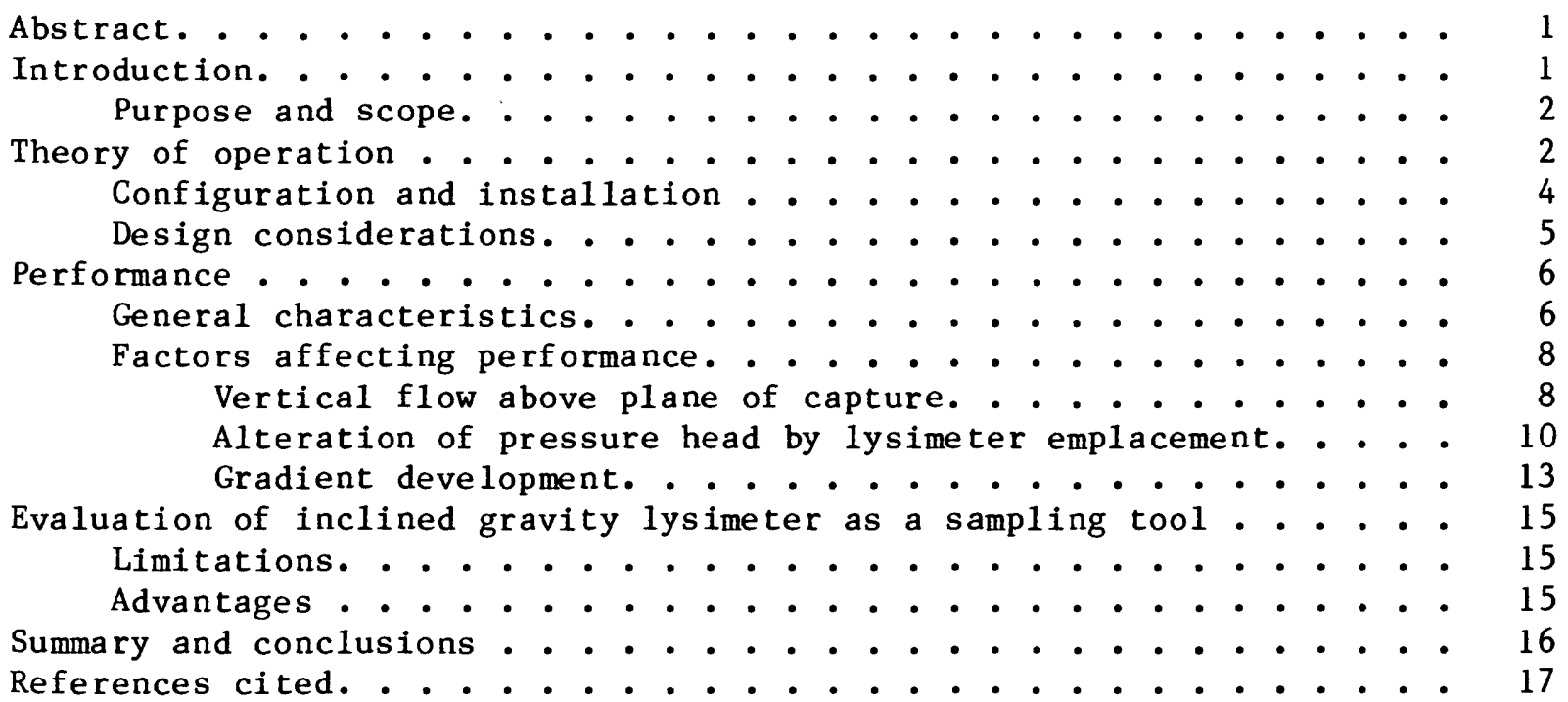

\section{ILLUSTRATIONS}

Figure 1. Sketch of inclined gravity lysimeter. . . . . . . . . . . 4

2. Sketch showing lysimeter dimensions controlling gradient. . 6

3. Graphs of " 100 percent capture" versus observed lysimeter outflows for lysimeters at leve $1 \mathrm{I}$, leve $1 \mathrm{II}$, and level III . . . . . . . . . . . . . . . . . . 7

4. Sketch showing location of neutron access tubes and lysimeters. . . . . . . . . . . . . . . . . . .

5. Graphs showing soil-moisture profiles: A, holes 5, 6, and 7 within the recharge basin; B, holes 3 and 4 outside the basin.................. 10

6. Sketch showing tensiometer network positioned around plane of capture at level II lysimeter..........

7. Graph showing effects of lysimeter presence on pressure head throughout the range of observed infiltration rates. . 


\section{ILLUSTRATIONS (continued)}

Page

Figure 8. Profiles of total head across and beyond the plane of capture at five infiltration rates. . . . . . . . . .

9. Graph showing comparison of gradients through lysimeter with those in the surrounding system over the range of observed infiltration rates... . . . . . . . . . 14

10. Graph of the infiltration rate versus ratio of lysimeter gradient to system gradient . . . . . . . . . . . 14

\section{CONVERSION FACTORS AND ABBREVIATIONS}

\section{Multiply SI $^{1}$ units}

millimeter $(\mathrm{mm})$
centimeter $(\mathrm{cm})$
meter (m)
square meter $\left(\mathrm{m}^{2}\right)$
liter (L)
meter per hour $(\mathrm{m} / \mathrm{h})$

By

To obtain inch-pound units

\section{Length}

$\begin{array}{ll}0.03937 & \text { inch (in) } \\ 0.3937 & \text { inch (in) } \\ 3.281 & \text { foot (ft) } \\ 10.76 & \text { square foot }\left(\mathrm{ft}^{2}\right) \\ 0.2642 & \text { gallon (ga1) } \\ 78.74 & \text { feet per day (ft/d) }\end{array}$

$1_{\text {International System of Units (SI) }}$ 


\title{
Hydraulic Considerations in Sampling the Unsaturated Zone with Inclined Gravity Lysimeters
}

By

E. T. Oaksford

\begin{abstract}
Inclined gravity lysimeters have been installed from an observation manhole to collect soil-water samples as deep as 5.39 meters below a small experimental recharge pond on Long Island, N.Y., and were shown to deliver 10 liters of sample per hour at an infiltration rate of 0.5 meter per hour. This represents a capture efficiency of approximately 50 percent, a value observed in two similar but shallower lysimeters. When lysimeters are installed from a trench or observation manhole, soil-water samples can be taken under virtually undisturbed conditions, avoiding the soil disturbance and filtration associated with porous-cup vacuum lysimeters. Successful operation requires that the sampler be designed for the hydraulic characteristics of the soil from which the sample is to be extracted. Criteria for lysimeter dimensions can be established on the basis of pressure heads observed during sampling, and soil water can be induced to flow into the lysimeter by gradient manipulation. Observed head gradients outside the lysimeter ranged between 1.7 and 2.2 times those across the lysimeter, which would explain the observed capture efficiency.
\end{abstract}

\section{INTRODUCTION}

Concern over ground-water pollution in many parts of the world has focused attention on the unsaturated zone as an important element in the retention or filtration of a variety of dissolved and suspended substances from surface sources. Understanding the movement of suspended and dissolved substances in the unsaturated zone requires that representative water samples be collected.

Sampling soil water from an unsaturated environment, in which pressure heads are less than atmospheric, poses a unique set of considerations and limitations. From the two basic sampling techniques described below, many variations have been developed, but each has certain drawbacks. Thus, selecting the most appropriate method and adapting it to the requirements of the particular soil medium and infiltration rate is of critical importance.

Soil-water samples have generally been collected by one of two means--a vacuum lysimeter or a gravity lysimeter. In the vacuum lysimeter, soil water is induced to flow through a porous membrane into a collection chamber maintained under vacuum. Wolff (1967) used this device in a weathering study in Maryland. Parizek and Lane (1970), Wood (1973), and Long (1978) modified this device to allow increased sampling depth and provide more chemically inert membrane materials. 
In a gravity lysimeter, percolating soil water flows by gravity through a conduit to a point of collection. This technique is commonly used in agricultural studies dealing with crop moisture needs and is generally used only in the upper few feet of soil. A variation on this technique is the gravity pan lysimeter (Parizek and Lane, 1970), in which a shallow pan serves as an impervious collection surface that funnels water to a collection bottle. The major limitation of the pan configuration is that surface tension at the outflow boundary severely inhibits sample collection at negative pressure heads (less than atmospheric pressure). Jordan (1968) designed a pan lysimeter in which tension-related effects are less severe. Although he gives no data, he states that collection efficiency is greatly improved at negative pressure heads. A disadvantage of his design, however, is that the sample is filtered by materials unlike the soils being sampled. In his version, glass wool and fiberglass screening were used.

\section{Purpose and Scope}

This report discusses the design, theory of operation, performance characteristics, and sampling implications of the inclined gravity lysimeter. This variation of a gravity lysimeter can be constructed to maximize capture efficiency and eliminate artificial filtration and is used most successfully in coarse, moist soils where access for installation is from a trench or observation manhole.

\section{THEORY OF OPERATION}

The theory of operation of the inclined gravity lysimeter is mathematically described by an extension of Darcy's Law for the special case of vertical unsaturated flow (Richards, 1931). The general equation written for unsaturated flow in a porous medium is:

$$
Q=-K\left(h_{P}\right) A\left(\frac{d h_{T}}{d l}\right)
$$

where:

$$
\begin{aligned}
& \mathrm{Q}=\text { discharge }\left(\mathrm{L}^{3} \mathrm{~T}^{-1}\right) \\
& \mathrm{K}\left(\mathrm{h}_{\mathrm{P}}\right)=\text { unsaturated hydraulic conductivity }\left(\mathrm{LT}^{-1}\right) \\
& \text { A }=\text { cross-sectional area }\left(\mathrm{L}^{2}\right) \\
& \mathrm{h}_{\mathrm{T}} \quad=\text { hydraulic head (L) } \\
& 1 \text { = linear distance (L) } \\
& \frac{\mathrm{dh}_{\mathrm{T}}}{\mathrm{dl}}=\text { rate of change in hydraulic head with distance in } \\
& \text { d1 the direction of flow }\left(\mathrm{L}^{\circ} \mathrm{M}^{\circ} \mathrm{T}^{\circ}\right)
\end{aligned}
$$


Hydraulic head can be expressed as

$$
h_{T}=h_{P}+z
$$

where $h_{p}$ is the pressure head and $z$ is the elevation head (positive upward). Substituting equation (2) into equation (1) gives:

where:

$$
Q=-K\left(h_{p}\right) A\left(\frac{d h_{p}}{d 1}+\frac{d z}{d 1}\right)
$$

$$
\begin{aligned}
& \mathrm{dh}_{\mathrm{P}}=\text { rate of change of pressure head with distance in the } \\
& \text { d1 direction of } f 1 \text { ow }\left(\mathrm{L}^{\circ} \mathrm{M}^{\circ} \mathrm{T}^{\circ}\right) \\
& \mathrm{dz}=\text { rate of change of elevation head with distance in the } \\
& \text { d1 direction of flow }\left(\mathrm{L}^{\circ} \mathrm{M}^{\circ} \mathrm{T}^{\circ}\right)
\end{aligned}
$$

If downward vertical flow is assumed to be positive, the change in distance along the flow path is equal to minus the change in elevation; that is,

$$
\mathrm{d} 1=-\mathrm{d} z
$$

Consequently, for positive downward vertical flow, equation (3) reduces to

where:

$$
\mathrm{Q}=\mathrm{K}\left(\mathrm{h}_{\mathrm{P}}\right) \mathrm{A}\left(\frac{\mathrm{dh_{ \textrm {P } }}}{\mathrm{dz}}+1\right)
$$

and

$$
\frac{d h_{P}}{d z}=\text { pressure-head component of hydraulic head gradient }
$$

$$
1 \text { = elevation-head component of hydraulic head gradient }
$$

Therefore, variations in vertical gradient in the unsaturated zone are dependent upon variations in the pressure-head component of the vertical gradient. Determining the quantity of water moving through the unsaturated zone is not simple because the hydraulic conductivity $(K)$ is not constant and is dependent upon the pressure head $\left(h_{p}\right)$. For unsaturated flow, pressure head is of ten referred to as soil-moisture tension, its negative equivalent.

To understand hydraulic gradients in the unsaturated zone in terms of their influence on the movement of water, consider the example of a column of porous medium with no upward or downward movement of water and a stationary water table. Under this condition, the gradient is zero, which means that the pressure-head component $\left(\mathrm{dh}_{\mathrm{p}} / \mathrm{dz}\right)$ is equal to -1 . To have positive flow downward, the hydraulic gradient must be greater than zero. Therefore the pressure-head gradient component must be greater than -1.0 . To accomplish this in unsaturated conditions, the change in soil-moisture tension $\left(-h_{P}\right)$ between two points must be slightly less than the vertical distance separating them. This gradient consideration was used to design the inclined gravity lysimeter. 


\section{Configuration and Installation}

The inclined gravity lysimeters discussed herein have been described by Prill, Oaksford, and Potorti (1979). The samplers were installed through the wall of an observation manhole in the center of a circular $24.55-\mathrm{m}^{2}$ recharge basin excavated in coarse outwash sand on Long Island, N.Y. The lysimeters are permanently positioned at depths of $0.68,2.26$, and $5.39 \mathrm{~m}$ below the recharge basin floor (see fig. 4, p. 9). A typical sampler (fig. 1) consists of (1) a square tube that extends diagonally upward through the manhole wall into the soil, and (2) a screened plate at the outflow end of the tube to hold sand and gravel in place. The sampler tube is made of 14-gauge stainless steel. The lysimeters are installed at an angle of $26.5^{\circ}$, creating a $1: 2$ slope. The collection end of the tube is beveled so that, when emplaced into the soil, it forms a horizontal plane of capture approximately $0.15 \mathrm{x} 0.3 \mathrm{~m}$.

The screened-plate assembly at the outflow end consists of a perforated stainless-steel plate overlain on the side facing the soil by a stainlesssteel screen. The assembly is placed inside the tube during installation and is positioned at the contact between the soil and the manhole. This position is maintained as the tube is driven past the plate into position with a hydraulic jack. As the tube is moved into position, it fills with soil.

Because the inclined gravity lysimeter cannot be installed from land surface, access at depth is required. Trenches or observation manholes are

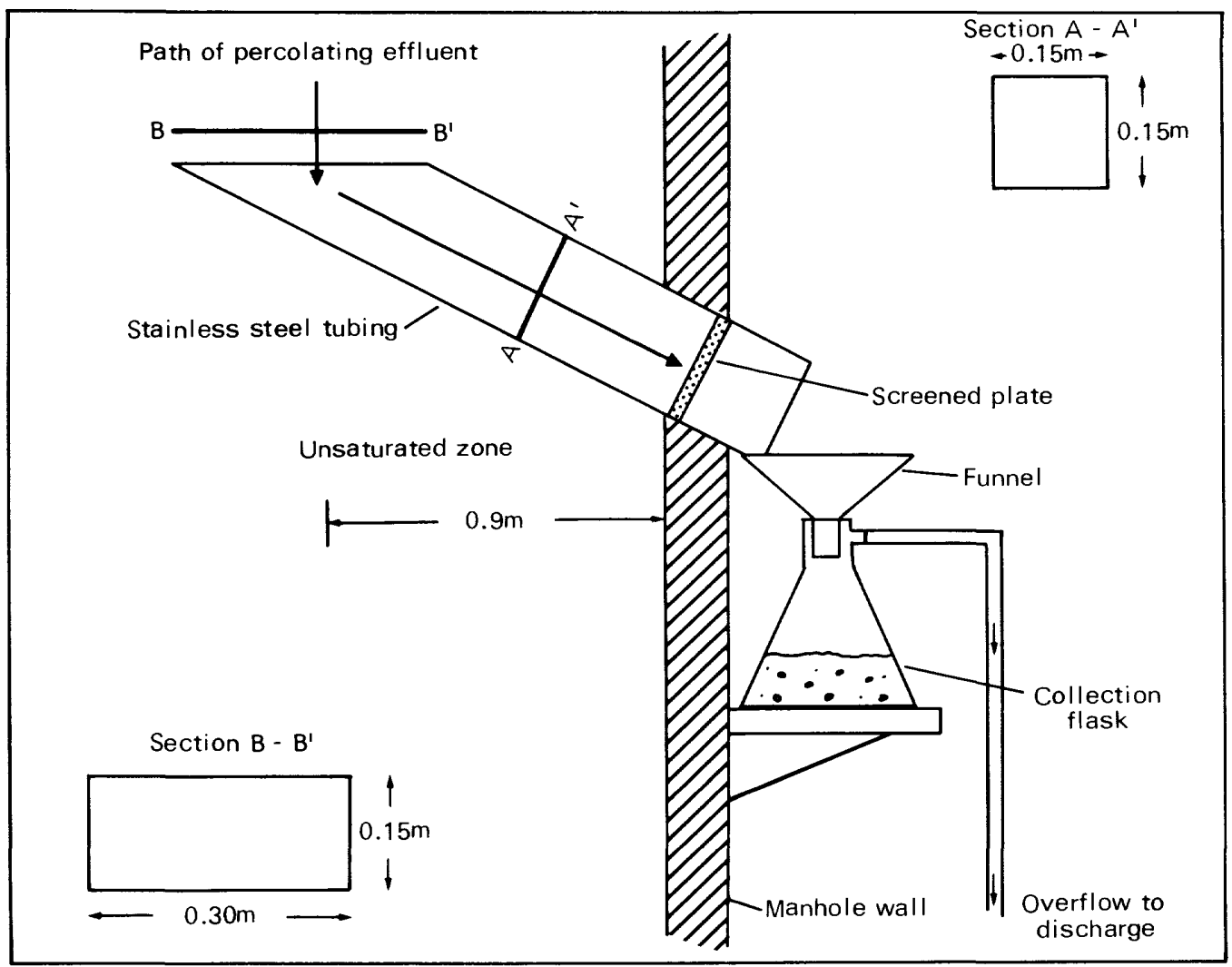

Eigure 1.--Inclined gravity lysimeter.

(Erom Prill and others, 1979.) 
the most practical solution to this requirement. Samplers should be made as short as possible for ease of installation and cost effectiveness. Two factors will determine the minimum lysimeter length and the angle of installation: (1) the horizontal distance from the manhole (or trench) to the plane of capture, and (2) the maximum soil tension under which samples are to be collected. After a minimum horizontal distance for the plane of capture has been established (usually the distance necessary to pass all disturbed soil adjacent to the trench or manhole), the maximum soil tension during collection dictates the vertical distance between the plane of capture and the outlet point and hence the angle of installation. The actual equivalent depth from which the sample is obtained is the sum of the depth from land surface to the plane of capture plus the distance through the lysimeter, which is dependent on the angle of installation. As a result, this places a limit on the minimum depth of sampling.

\section{Design Considerations}

At any given elevation head, water does not flow from a zone of negative pressure head to a zone of positive pressure head. For the same reason, the lysimeter tube must be inclined in accordance with the head gradient that is required for downward flow under the pressure heads present in the formation at the time of sampling to capture water. For an inclined gravity sampler, the pressure head at the outlet is by definition equal to atmospheric pressure, or $0.0 \mathrm{~cm}$ of water. The lysimeter dimensions and angle of installation must be predetermined to ensure that the total head gradient within the lysimeter is greater than zero. The most significant element of the design is the vertical distance between the plane of capture and the point of collection. This distance must be greater than the greatest soil tension $\left(-h_{p}\right)$ experienced during sampling. This can be explained by examining the physical elements of the lysimeter and outlining the computation of gradient based on actual dimensions. Figure 2 shows the dimensions of the lysimeter necessary to compute the gradient. Assuming that flow within the lysimeter is one-dimensional and parallel to the axis of the lysimeter, and that hydraulic conductivity is constant and uniform within the lysimeter, flow through the lysimeter would be described by:

$$
Q=K A\left(\frac{H_{A}-H_{B}}{L}\right)
$$

where:

$$
\begin{aligned}
\frac{\mathrm{H}_{A}-\mathrm{H}_{B}}{\mathrm{~L}} & =\text { hydraulic gradient through the lysimeter } \\
\mathrm{H}_{\mathrm{A}} & =\text { total head at } \mathrm{A} \text { (pressure head plus elevation head) } \\
\mathrm{H}_{B} & =\text { total head at } B \text { (pressure head plus elevation head) and } \\
L & =\text { distance between points } A \text { and } B
\end{aligned}
$$




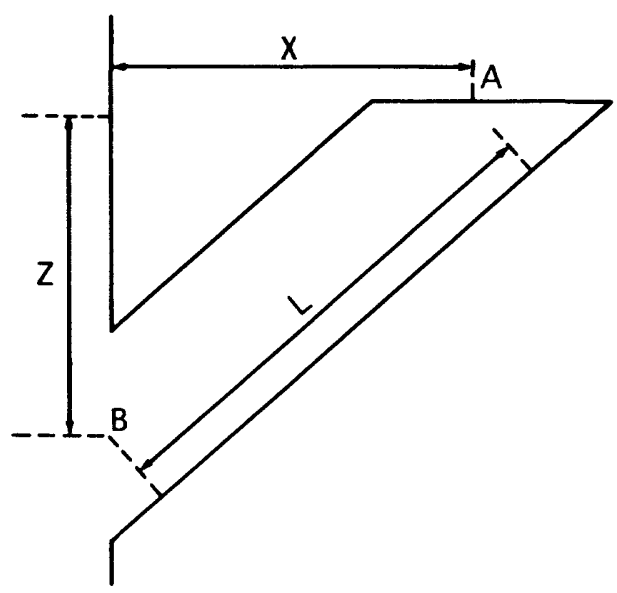

\author{
Figure 2 \\ Lysimeter dimensions \\ controlling gradient.
}

From equation 6 it can be seen that the numerator of the gradient must be greater than zero to create a gradient conducive to flow through the lysimeter. From figure 2, the elevation head at point $B$ can be made zero by defining the datum at that point. Therefore, the total head at $B$ will be zero because the pressure head is also zero, or atmospheric. This leaves the total head at $A$ as the determining factor in the numerator, which means that the sum of the pressure head and elevation head must be greater than zero to generate a positive gradient. For a gradient of 1 to be achieved, the total head at $A$ must be equal to $\mathrm{L}$. This is important because the lysimeter is always competing with the surrounding system for flow. In coarse glacial outwash deposits, a system gradient of 1 , or that due solely to gravity, is usually a reliable estimate as to the gradient against which the lysimeter will be competing. For this reason it is important that the sampler be designed to develop a gradient as close to 1 as possible while keeping the sampler as short as possible for ease of installation.

\title{
PERFORMANCE
}

\section{General Characteristics}

The efficiency of three lysimeters installed beneath a small recharge basin excavated in coarse sand on Long Island, N.Y., is plotted in figure 3. The graphs represent the actual and " 100 percent capture" outflows for three lysimeters at various infiltration rates. The curves for "100 percent capture" outflow are calculated by multiplying the infiltration rate by the area of capture. They are identical for all three lysimeters because basin infiltration rate is assumed to be uniform and because all lysimeters have the same capture-surface area. The curves for actual outflow were constructed by a least-squares fit of the observed data points to the linear equation $y=a x$. The slope of the fitţed lines for actual outflows from the lysimeters at levels I and III average approximately 53 percent of the "100 percent capture" outflows. The scatter of data points at level I, particularly at high infiltration rates, probably reflects the fact that the plane of capture's altitude is above the bottom of the basin's retaining wall. In addition, the infiltration rate is not truly uniform, even in such a small basin. Therefore, effects of the retaining wall on the uppermost lysimeter would accentuate any ronuniformity of infiltration rate, causing greater variability in outflow rate. The slope of the fitted line for actual flow from lysimeter II was only 

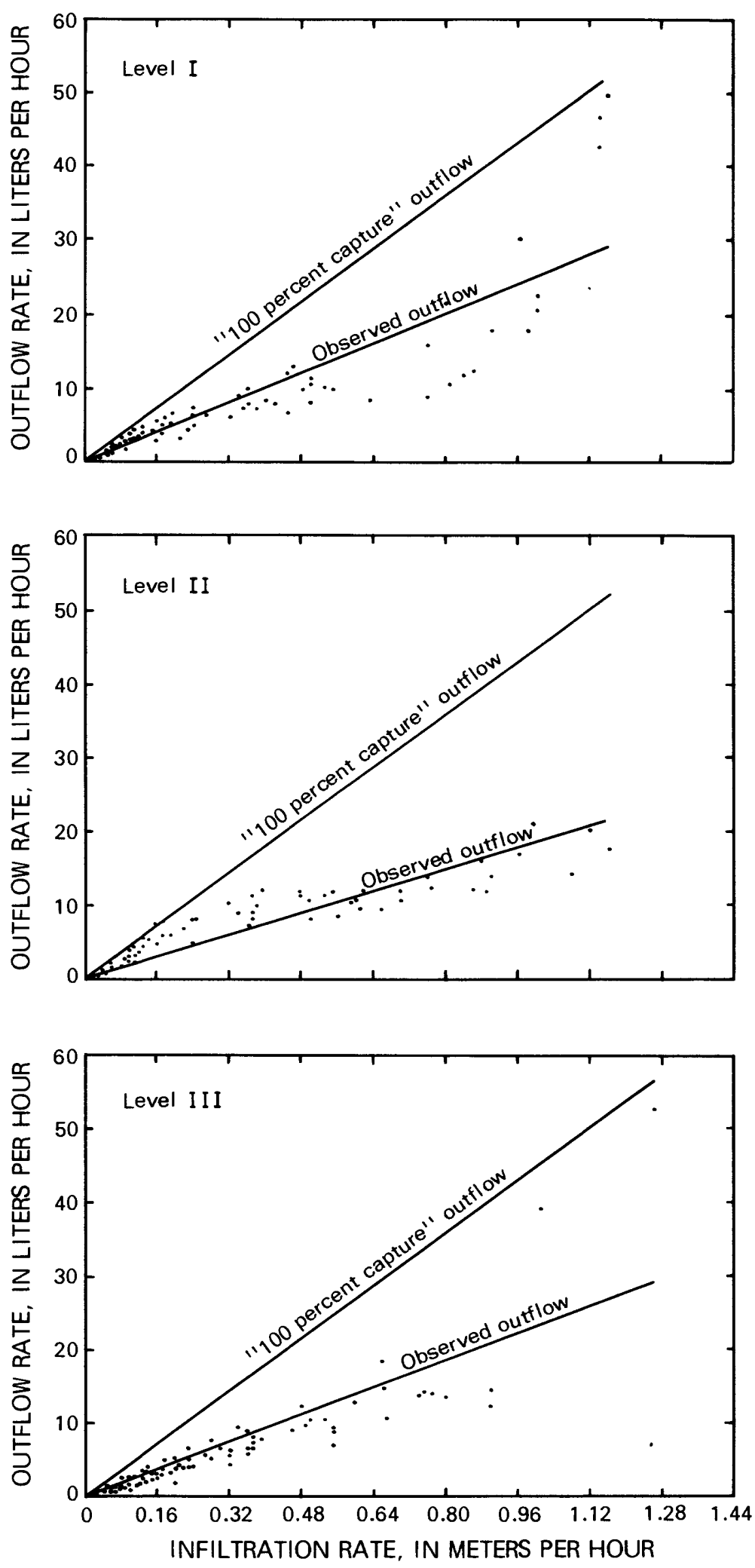

Figure 3.--"100 percent capture" versus observed outflows for lysimeters at level I, level II, and level III. 
40 percent of the "100 percent capture" outflow. This somewhat lower value for lysimeter II is attributéd to a nest of tensiometers that was installed directly above and around the level II lysimeter. Although the tensiometers are small, they probably caused diversions that resulted in slightly smaller outflows than were observed in the lysimeters not instrumented with

tensiometers. (The tensiometers were installed only at level II; they were used to study pressure-head variations during sample collection at various infiltration rates and are discussed later.) Without the tensiometers, the fitted slope for actual outflow at lysimeter II would be expected to be nearly equal to those of the other lysimeters.

\section{Factors Affecting Performance}

\section{Vertical flow above the plane of capture}

Moisture logs indicate that flow through the unsaturated zone was mostly vertical. The proportion of water moving horizontally beyond the periphery of the basin was small, as indicated by the much higher moisture content recorded at access holes inside the basin than at those outside. A plan and profile view showing the location of the moisture-logging access holes is shown in figure 4; an example of the moisture differences as provided by logs run on November 12,1975 , the 6 th day of a recharge test, when the infiltration rate was $1.30 \mathrm{~m} / \mathrm{h}$, is given in figure 5. Figure $5 \mathrm{~A}$ depicts logs for holes 5,6 , and 7 , inside the basin at distances of $0.61,1.22$ and $0.91 \mathrm{~m}$ from the perimeter, respectively, with a background $\log$ from hole 7 included for reference; figure 5B shows moisture logs taken the same day at access holes 4 and 3 , which are $0.91 \mathrm{~m}$ and $1.83 \mathrm{~m}$ outside the perimeter of the basin, respectively.

The logs for the three holes inside the basin (fig. 5A) are similar to one another, which indicates that the rate of flow beneath the basin was nearly uniform. Most of the soil-moisture values we re between 35 and 40 percent. Moisture values at hole $4,0.91 \mathrm{~m}$ outside the basin, were 8 percent lower than those inside the basin, and those at hole $3,1.82 \mathrm{~m}$ outside the basin, were 15 percent lower (fig 5B). The logs for the two access holes outside the basin show markedly lower moisture content than those inside the basin and indicate that the quantity of water flowing laterally beyond the basin boundaries was very small, even at the highest infiltration rates.

The similarity of moisture logs from beneath the basin (fig. 5A), and the markedly lower moisture values just outside the basin (fig. 5B), indicate that not only does an extremely large proportion of the infiltrating water move directly downward, but that lateral diversion occurs only near the periphery of the basin. Otherwise moisture values would be progressively higher toward the basin center. In other words, the water contributing to increased moisture content outside the basin was derived from the outermost edges of the basin. It seems reasonable to assume that flow $0.91 \mathrm{~m}$ inside the retaining wall, the point of the three lysimeters' plane of capture, was indeed vertical and that basing the computation of "100 percent capture" on actual infiltration rate is justified. This also suggests that the actual observed capture efficiency of the lysimeter is due only to diversion of flow around and away from the lysimeter, not to any loss prior to capture. 


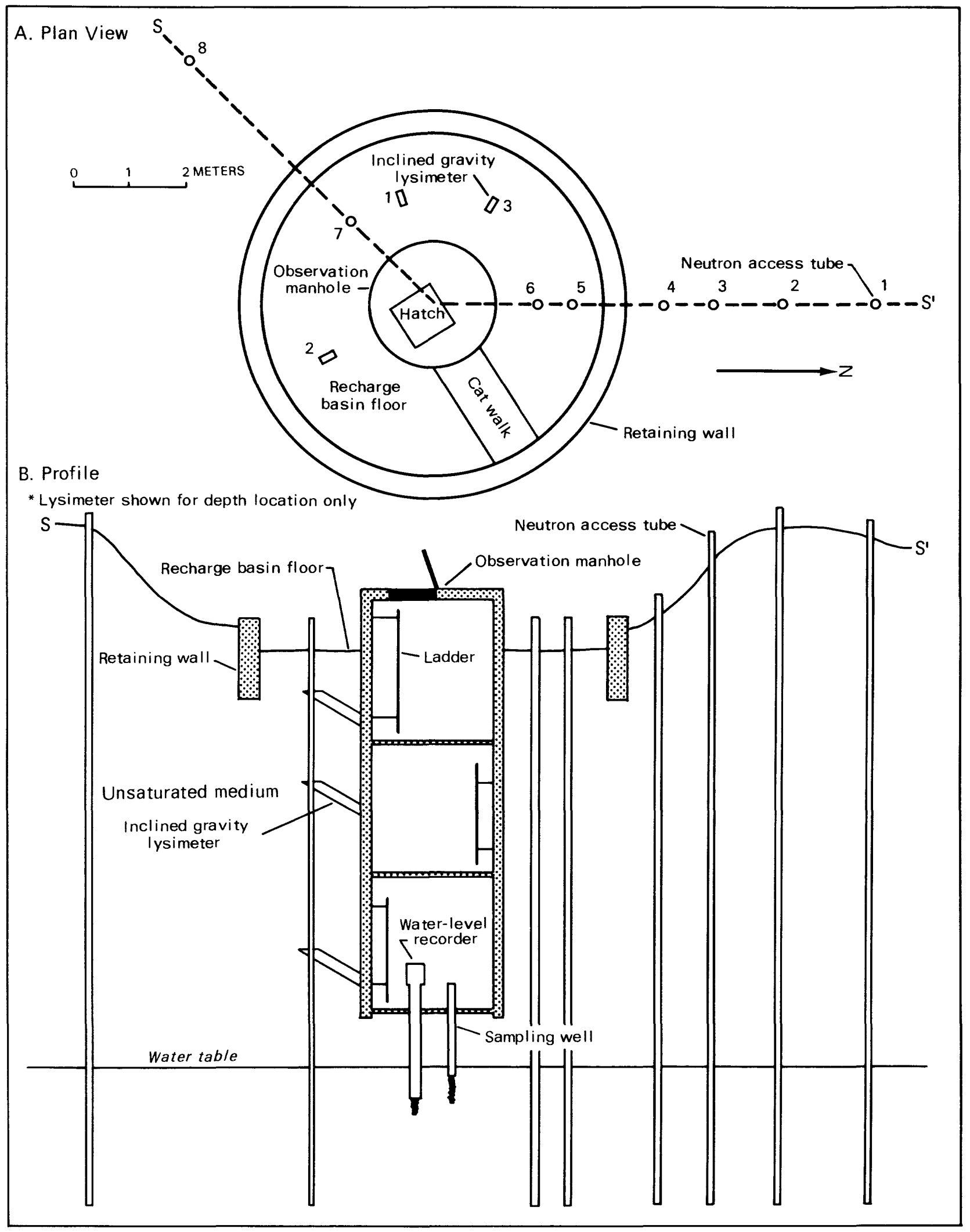

Figure 4.--Location of neutron access tubes and lysimeters. (Modified from Prill and others, 1979.) 


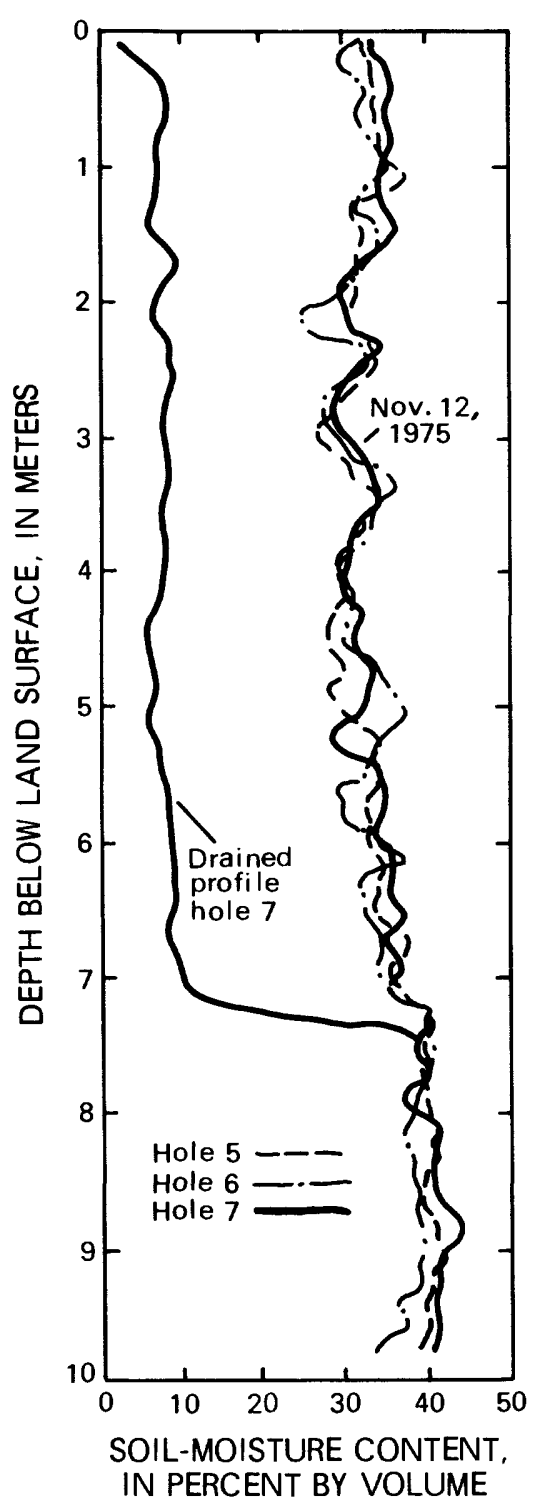

A
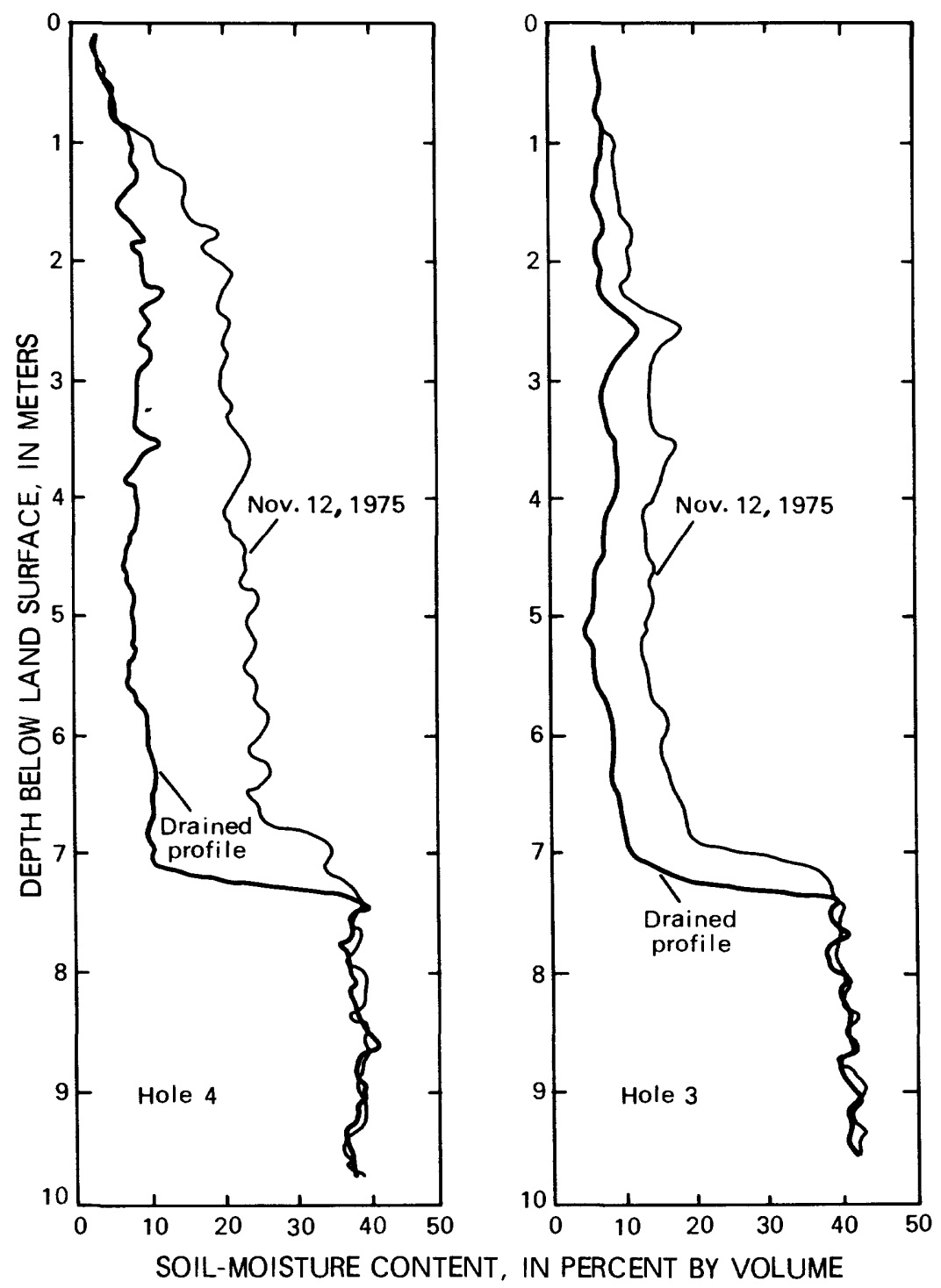

B

Figure 5.--Soil-moisture profiles: A, holes 5, 6, and 7 within the recharge basin; $B$, holes 3 and 4 outside the recharge basin.

\section{Alteration of pressure head by lysimeter emplacement}

To study the effects the lysimeter imposed on the system while providing a means of sampling, a nest of tensiometers was laterally installed directly above and adjacent to the plane of capture at the level II lysimeter. Having a diameter of $0.95 \mathrm{~cm}$, the tensiometer tubes cast a slight hydraulic shadow on the plane of capture, as mentioned earlier. A front and plan view of their positions are given in figure 6 with a table of horizontal distances from the center of the lysimeter plane of capture and vertical distances above it. 


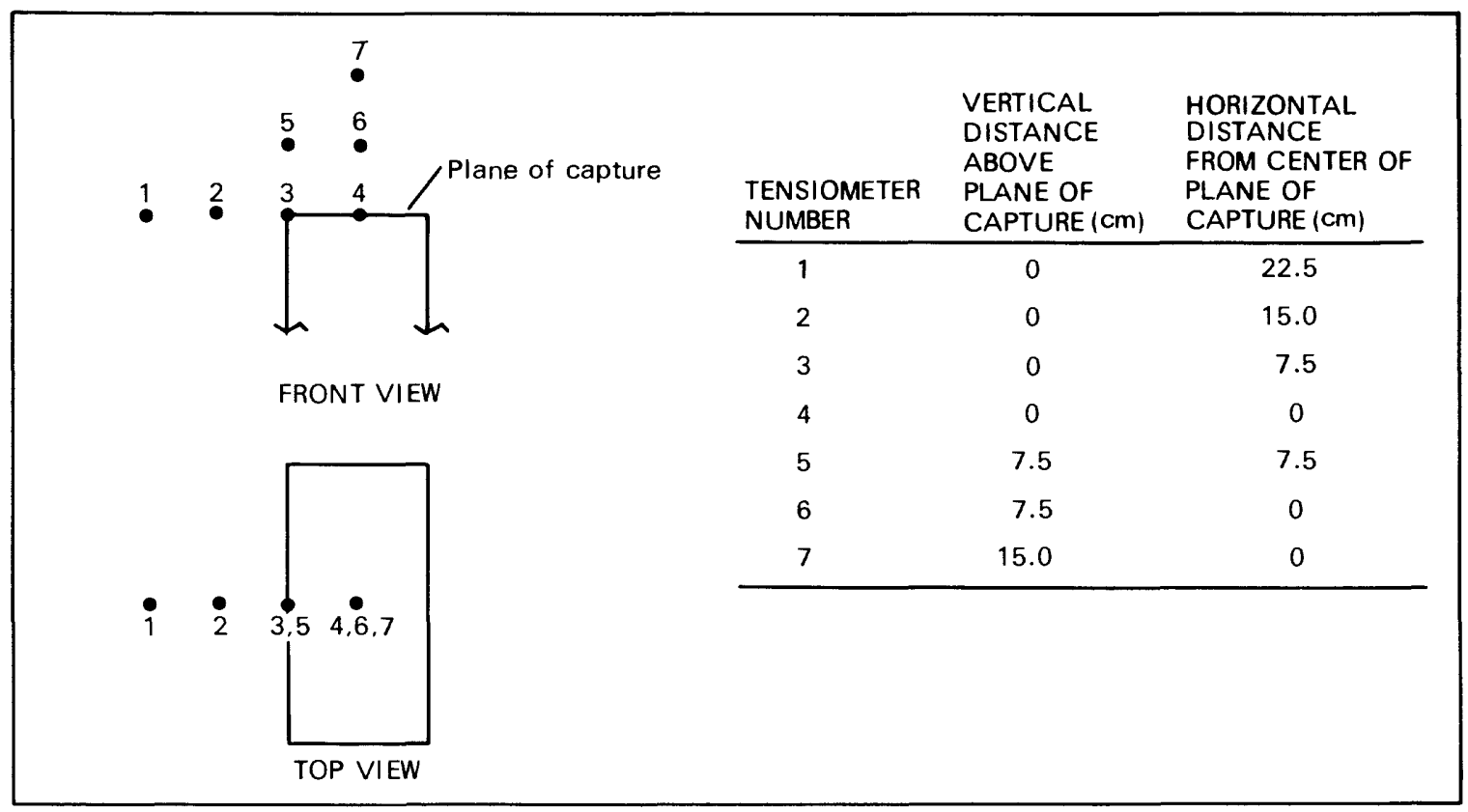

Figure 6.--Tensiometer network positioned around plane of capture at level II lysimeter.

The relationship between soil-moisture tension and infiltration rate provided a means of examining the pressure-head effects of lysimeter emplacement. To depict this relationship, a comparison of pressure-head values at two tensiometers was made through a wide range of infiltration rates. One tensiometer, no. 4, was placed in the center of the lysimeter's plane of capture (fig. 6); the other (not shown) was placed at the same altitude but removed beyond any possible hydraulic influence caused by the lysimeter. Results of the comparison are shown in figure 7. The curve for the tensiometer representing the unaffected area shows the typical relationship for the coarse soil at the site. The notable characteristic of this curve is that, at pressure heads above $-10 \mathrm{~cm}$ of water, large increases in infiltration rate are accompanied by small increases in pressure head. Below this value, any change in infiltration rate is accompanied by a much greater change in pressure head. In contrast, the curve representing the area affected by the lysimeter illustrates two major points: (1) pressure heads at a given infiltration rate are consistently higher above the lysimeter than in the surrounding unaffected area; and (2) for a given change in infiltration rate, the resulting change in pressure head above the lysimeter is only slightly greater than in the surrounding unaffected area. Although the tensiometers themselves cause a slight pressure-head buildup that is compounded by their proximity to one another, the consistently higher heads above the lysimeter come about primarily because the lysimeter is an obstacle in the path of percolating water.

Another representation of the pressure-head effects resulting from lysimeter emplacement is shown in figure 8, where horizontal total head profiles are shown across the lysimeter's plane of capture at different infiltration rates. The data were obtained from tensiometers $1,2,3$, and 4. 


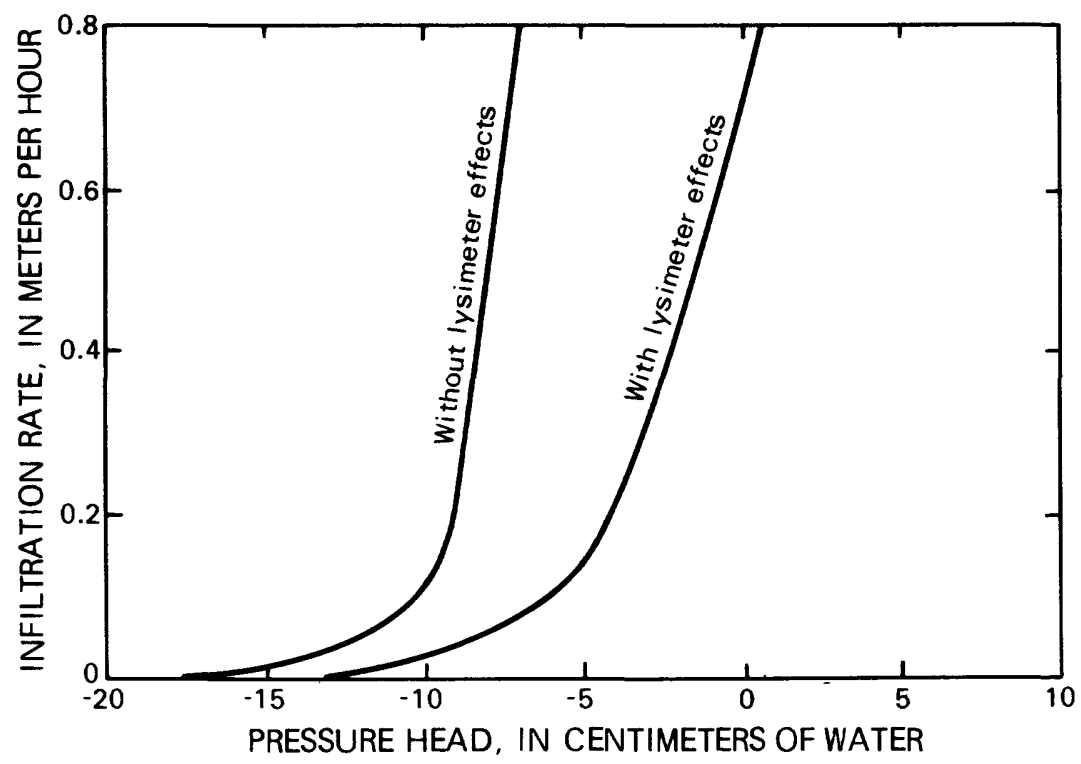

Figure 7.--Effects of lysimeter presence on pressure head throughout range of observed infiltration rates

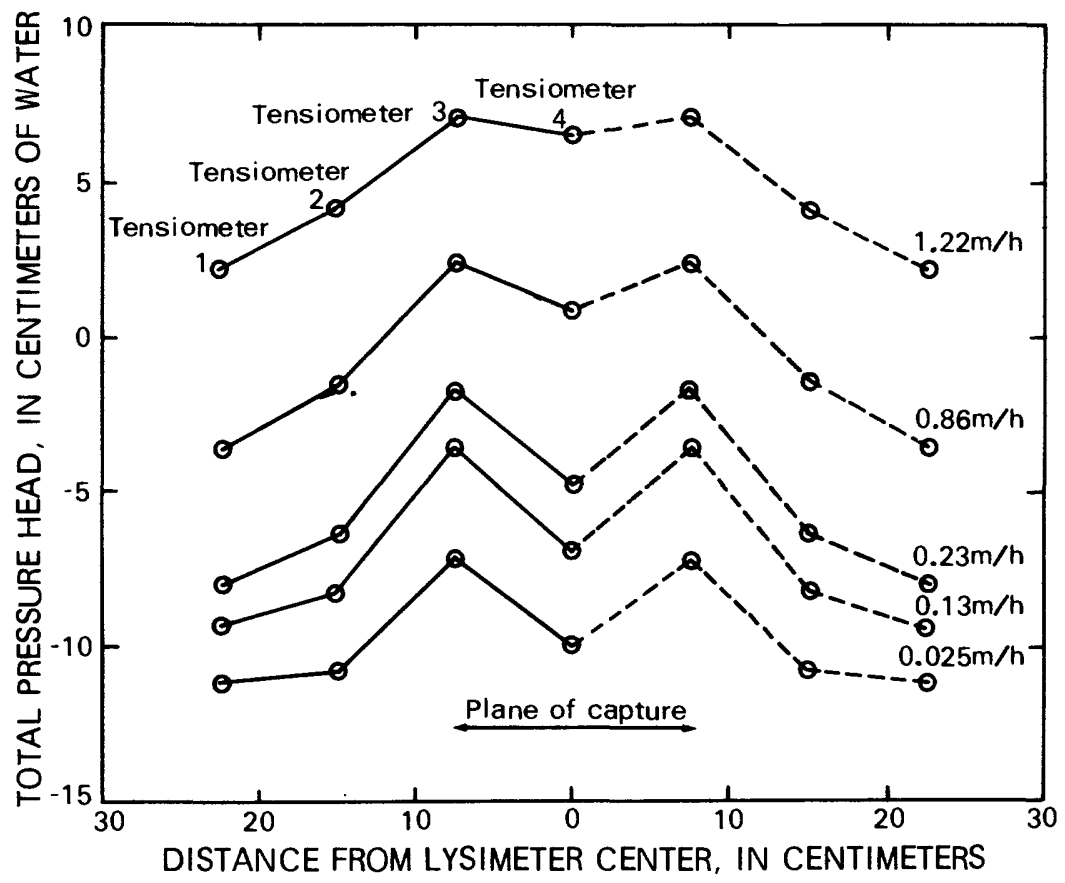

Figure 8.--Profizes of total pressure head across and beyond plane of capture at five infiltration rates. (Placement of tensiometers is shown in fig. 6.) Dashed lines indicate inferred values on opposite side of plane of capture. 
A mirror image of the data is included on the assumption that the effect is symmetric. Particularly noticeable is the overall head increase in the profiles as infiltration rate increases. Also evident is the decrease in lateral gradient within the confines of the plane of capture as infiltration rate increases. It might be reasonable to assume that an uninstrumented lysimeter (one without tensiometers above and around the plane of capture) would produce slightly more uniform horizontal pressure profiles throughout the same range of infiltration rates.

\section{Gradient Development}

Hydraulic gradient and hydraulic conductivity, which are functions of pressure head (or moisture content), dictate the lysimeter's capture efficiency, and changes in these elements, both in the lysimeter itself and in the system, influence the capture efficiency. Because of the complexity of evaluating both hydraulic conductivity and the effects of any required instrumentation, the hydraulic gradients both through the lysimeter and in a general region unaffected by the lysimeter's presence we re analyzed. The relationship of these gradients over a range of hydraulic conditions presents an overall picture of hydraulic response in the lysimeter as well as the system as a whole, and also seems to reflect the volume of flow that the lysimeter will capture.

The geometry of the 1ysimeter determines the hydraulic response reflected in this gradient relationship. In this case the horizontal plane of capture, from which the " 100 percent" capture was calculated, was twice that of the cross-sectional area perpendicular to the lysimeter tube. The cross-sectional area, as well as the angle of emplacement, affects the uniformity of moisture concentration in the lysimeter, and the result is an irregular gradient, an irregular flow field, and elevated pressure heads above the plane of capture. In fact, the lysimeter geometry and its effects on moisture concentration may cause the point of atmospheric, or zero, pressure to be located not only at the point of outflow, but along some saturated free-surface boundary within the lysimeter. The overall effect of this, however, would have little effect on the gradient through the lysimeter computed between points A and B (fig. 4) because pressure head at point $B$ could not attain a value greater than $0 \mathrm{~cm}$ of water, even if atmospheric pressure occurred above this point elsewhere in the lysimeter. The effect of this irregular distribution would be to alter significantly the uniformity of the gradient within the lysimeter, causing greater head loss in some parts of the lysimeter than in others. Although head distribution within the lysimeter was not studied in detail, it is sufficient to recognize that its probable lack of uniformity has little bearing on the overall gradient and therefore does not rule out the use of a gradient analysis to characterize the lysimeter's ability to capture water.

Figure 9 is a plot of the gradient through the lysimeter against the ambient system gradient over a full range of infiltration rates. This figure indicates that neither the lysimeter gradient nor the system gradient varied significantly with changes in infiltration rate; most points are clustered near a system gradient of 1 and a lysimeter gradient of 0.5 . In soils where 


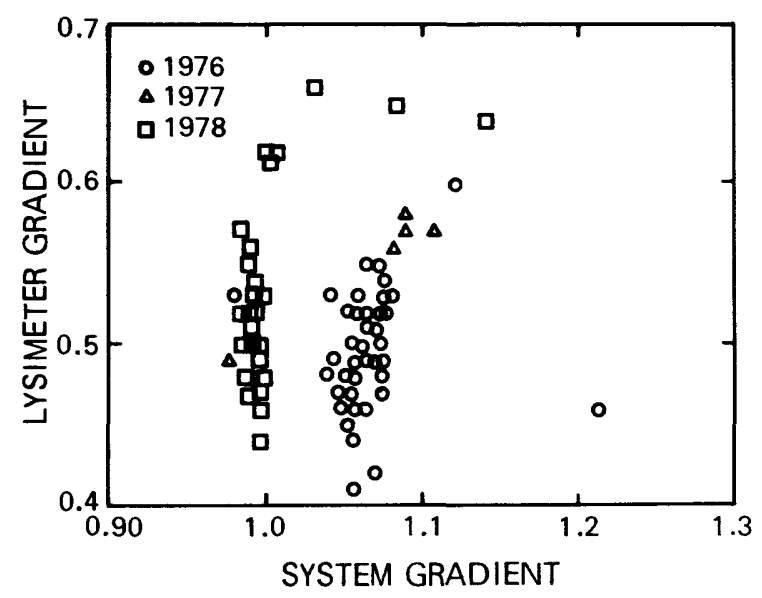

Figure 9

Comparison of gradients

through the lysimeter

with those in the surround-

ing system over the range of

observed infiltration rates.

this lysimeter's use is feasible, it would seem that once a particular lysimeter configuration is chosen, the gradient conditions around the lysimeter in relation to the overall system remain relatively consistent and would not be significantly affected by infiltration rate. Consequently, any changes in the ratio of lysimeter gradient to system gradient are not likely to be great. This point is made more clear by figure 10 , in which the ratio of the lysimeter gradient to system gradient is plotted against infiltration rate. The data in this figure indicate the tendency for water to flow into the lysimeter, and this tendency seems to remain relatively consistent through the entire range of observed infiltration rates. This relatively consistent gradient ratio of approximately 0.5 is roughly equivalent to the ratio between the slope of observed lysimeter outflows and the slope of the "100 percent capture" lysimeter outflow. In other words, the gradient ratio seems to

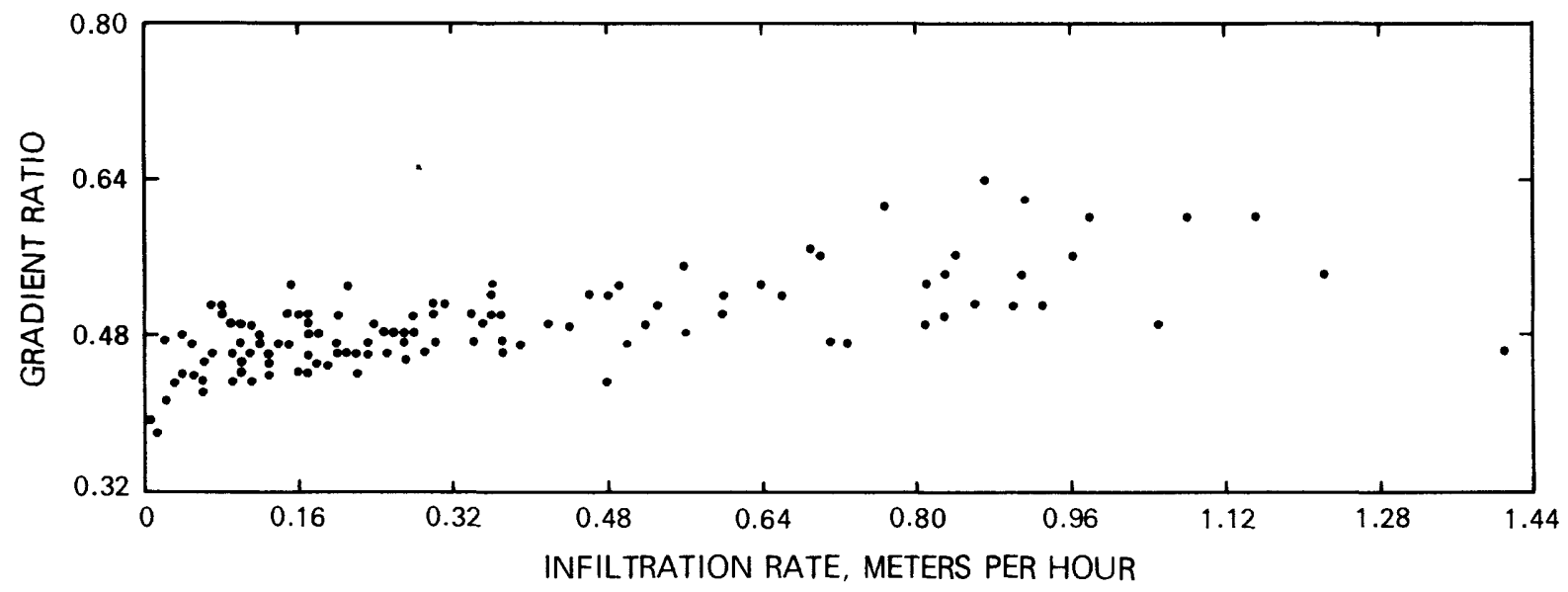

Figure 10.--Plot of infiltration rate versus ratio of lysimeter gradient to system gradient. 
provide a quantitative estimate for the observed capture efficiency of the lysimeters. The significance of such a relationship is difficult to assess. However, the gradient ratio is a composite variable into which many complex, virtually immeasurable effects are grouped and may provide a logical, objective means of verifying observed lysimeter capabilities over a wide range of hydraulic conditions.

\section{EVALUATION OF THE INCLINED GRAVITY LYSIMETER AS A SAMPLING TOOL}

\section{Limitations}

The greatest limitations in the use of the inclined gravity lysimeter are related to its installation, which would generally restrict its use to situations where pressure-head values are between 0 and $-60 \mathrm{~cm}$ of water. The inclined gravity lysimeter could be used under sampling conditions where pressure heads are less, but its design and dimensions would make proper installation extremely difficult.

The lysimeters described in this report have been evaluated only under constant water application, so that the lysimeter outflow characteristics presented may bear little relation to those encountered in a system in which water is applied intermittently. The latter condition could create preferential flow paths that could easily be changed by the duration and the magnitude of water applied. Capture characteristics would then vary with application conditions. Although the lysimeters would deliver water under these circumstances, the capture would depend on variables not addressed in this report and would probably bear little relation to the data presented.

If samples were to be collected very near the land surface, the depth of the capture plane would be another limitation. As mentioned earlier, soilmoisture tension determines the vertical distance between the capture plane and point of collection (points $A$ and $B$, respectively, in fig. 4). Because the sample must flow through soil in the lysimeter, the actual sampling depth depends on the length of the lysimeter. Therefore, if the depth were less than the soil-moisture tension during sampling at the plane of capture, water would not flow into the lysimeter.

\section{Advantages}

The shortcomings that make the porous-cup vacuum lysimeter undesirable for soil-water sampling do not affect the inclined gravity lysimeter. Many of the inadequacies of vacuum lysimeters have been pointed out by Hansen and Harris (1975), whose study indicates substantial bias and variability when porous-cup vacuum lysimeters we re used to characterize nitrogen and phosphorus concentrations in soil water. Sources of bias we re sorption, leaching, diffusion, and ion screening; sources of variability were sampler intake rate, cup clogging, sampler depth, and type of vacuum system. More important, Shaffer and others (1979) concluded that porous-cup vacuum lysimeters were not suitable for monitoring the chemical quality of water percolating through coarse, moist soil. In their comparison of soil-water samples from the roof of a horizontal tunnel with those from porous-cup vacuum lysimeters, the 
porous cup was found ineffective in extracting water from soil pores with pressure heads greater than $-20 \mathrm{~cm}$ of water. Because 90 percent of the total flow in coarse soils occurs in pores at pressure heads of $-20 \mathrm{~cm}$ of water and greater, the porous-cup vacuum lysimeter is clearly a poor choice.

The inclined gravity lysimeter is successful because it causes minimal interference with flow conditions, avoids prefiltering or imposing a vacuum on the sample, and captures rapidly flowing water from pore channels with pressure heads greater than $-20 \mathrm{~cm}$ of water.

In respect to flow characteristics around the inclined gravity sampler, the only limitation is its inherent capture efficiency, which will generally be less than 100 percent because of physical limitations.

\section{SUMMARY AND CONCLUSIONS}

An inclined gravity lysimeter can be used to collect soil-water samples from coarse, moist sand and gravel under virtually undisturbed conditions, the reby avoiding the inadequacies of porous-cup vacuum lysimeters. By the principle that hydraulic gradient is the initiative to flow, soil water can be induced to flow into the lysimeter if the sampler dimensions and emplacement angle are adjusted to the sampling environment. Complexity of flow within and around a given lysimeter configuration makes prediction of actual outflows difficult.

From the data presented here, the ratio of observed outflow to " 100 percent capture" outflow reflects the ratio of the gradient through the lysimeter to the gradient in the unsaturated system through a wide range of infiltration rates and thus provides an indirect means of assessing gradient relationships between the lysimeter and the surrounding medium.

The description of concepts in this report points out the criteria relevant to the design and installation of a lysimeter of the type described. Knowledge of the sampling environment and its degree of saturation is critical in choosing and customizing a suitable means for sample extraction. Because a lysimeter of this type has many advantages over the porous-cup vacuum type in coarser soils, it is likely to find increased application. The porous-cup vacuum lysimeter must still play an important role in studies of the unsaturated zone, but the inclined gravity lysimeter is clearly preferable wherever conditions permit. 


\section{REFERENCES CITED}

Hansen, E. A., and Harris, A. R., 1975, Validity of soil-water samples collected with porous ceramic cups: Soil Science Society of America Proceedings, v. 39, p. 528-536.

Jordan, C. F., 1968, A simple, tension-free lysimeter: Soil Science, v. 105, no. 2 , p. $81-86$.

Long, L. F., 1978, Notes on a glass filter soil solution sampler: Soil Science Society of America Journal, v. 42, p. 834-835.

Parizek, R. R., and Lane, B. E., 1970, Soil-water sampling using pan and deep pressure-vacuum 1ysimeters: Journal of Hydrology, v. 11, p. 1-21.

Pri11, R. C., Oaksford, E. T., and Potorti, J. E., 1979, A facility designed to monitor the unsaturated zone during infiltration of tertiary-treated sewage, Long Island, New York: U.S. Geological Survey Water-Resources Investigations $79-48, \mathrm{p} .14$.

Richards, L. A., 1931, Capillary conduction of liquids through porous media: Physics, v. 1, p. 318-333.

Shaffer, K. A., Fritton, D. D., and Baker, D. E., 1979, Drainage water sampling in a wet, dual-pore soil system: Journal of Environmental quality, v. 8 , no. 2 , p. 241-246.

Wolff, R. G.,1967, Weathering of Woodstock Granite near Baltimore, Maryland: Americal Journal of Science, v. 265, p. 106-117.

Wood, Warren W., 1973, A technique using porous cups for water sampling at any depth in the unsaturated zone: Water Resources Research, v. 9, no. 2, p. 486-488. 